
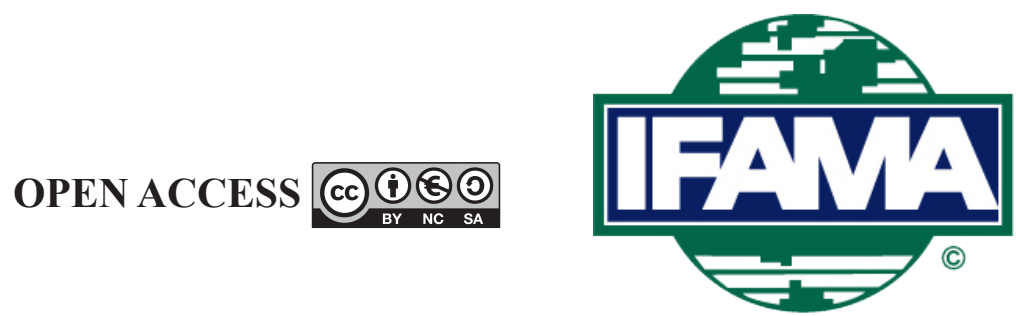

International Food and Agribusiness Management Review

Volume 24, Issue 3, 2021; DOI: 10.22434/IFAMR2020.0040

Received: 17 March 2020 / Accepted: 11 January 2021

\title{
Product differentiation and brand building: a hedonic analysis of yogurt price in China
}

\section{RESEARCH ARTICLE}

\author{
Bo Chen ${ }^{\mathrm{a}}$, Xiaoheng Zhang ${ }^{\mathrm{b}}$ and Qingjie Zhou ${ }^{\circledR \mathrm{C}}$ \\ ${ }^{a}$ Associate Professor, School of Economics, Nanjing University of Finance and Economics, \\ No.3 Wenyuan Road, Xianlin College Town, Nanjing, 210023, China P.R. \\ ${ }^{b}$ Associate Professor, College of Economics and Management, Nanjing University of Aeronautics \\ and Astronautics, No. 29 Jiangjun Road, Jiangning District, Nanjing, 211106, China P.R.
}

'Professor, School of Economics, Beijing Technology and Business University, 33 Fucheng Road, Haidian District, Beijing, 102488, China P.R.

\begin{abstract}
The Chinese yogurt market has seen strong growth in recent years. To meet consumers' diverse demand, yogurt manufacturers have invested substantially in product and brand strategies - they not only introduce new attributes to yogurt, but also create sub-brands with distinct product positioning. However, little is known regarding the effectiveness of these strategies. We fill this research gap by estimating the price premiums associated with main yogurt attributes and brands using a hedonic analysis framework. Our main findings are that plain flavored yogurt and yogurt with sugar are associated with negative price premiums while having fat, having probiotics, ambient and being designed for kids are associated with positive price premiums. Moreover, sub-brand effect plays an important role in consumer's valuation of yogurt due to their distinct product positioning, and sub-brands that position themselves as natural, ambient, European-style, traditional style, fruits and grains, and for children have high price premium.
\end{abstract}

Keywords: yogurt, hedonic analysis, brand, price JEL code: Q11, M30

(i)Corresponding author: zhouqj@btbu.edu.cn 


\section{Introduction}

China was one of the countries with the lowest consumption of dairy products per capita around the world. As of 2004, average dairy consumption with milk equivalent was only $22 \mathrm{~kg}$, comparing with $93 \mathrm{~kg}$ in India and over $150 \mathrm{~kg}$ in North America and Europe at the same time (Hemme and Otte, 2010). However, dairy consumption as well as production has been increasing rapidly since then, with annual per-capita dairy consumption reaching $36 \mathrm{~kg}$ in 2019 (Wenqian, 2019). Given that China has the largest population of 1.3 billion, this growth is phenomenal. Several reinforcing factors are shown to contribute to this strong growth, including income growth, promotion by the government and dairy industry, urbanization, and development of marketing channels (Fuller et al., 2006). Yet, the long-run trend was once disrupted by the melamine milk scandal in 2008, which had a profound impact on the Chinese dairy sector - not only it led to the restructuring of the entire dairy industry but also it contributed to the ever tightening of food safety regulation in China. The repercussion of this incident can still be felt today as food safety remains one of consumers' top concerns.

After the incident, Chinese consumers have gradually regained confidence in domestic dairy products. As a result, dairy consumption has resumed previous growth trend, and the then Ministry of Agriculture further predicted that the import of dairy products will increase at an annual rate of 50\% from 2016 to 2026 (China Ministry of Agriculture, 2017). However, not all dairy products will experience the same growth rate, and dairy consumption is trending towards yogurt - the total sale of yogurt increased by $108.6 \%$ from 2013 to 2017 , in contrast to $18 \%$ of milk (Wenqian, 2017). The popularity of yogurt is particularly driven by Chinese consumers' increasing health conscious. Demand for nutritious food with additional health benefits is increasing, and yogurt meets this description as it is not only a good source of multiple nutrients but also helps digestion and improving immune system (DaxueConsulting, 2019).

The yogurt industry in China is competitive with many brands. The three leading national dairy manufacturers - Bright from Shanghai, Yili, and Mengniu from Inner Mongolia - have a combined market share of 63\% in 2018 (ChinaAg, 2018). In addition, small local brands compete with the three national brands in their respective regions. Some of these local brands expand rapidly to other cities, e.g. Junlebao is originally a local brand from Hebei province, but it can also be found in many other cities in China. While other local brands may still operate only in their origin cities and offer a limited range of products. Furthermore, the fast growth of the yogurt market has attracted international brands with Danone a major competitor nationally.

To compete for market share and meet consumers' diverse preferences, most yogurt manufacturers differentiate their products, and thus yogurt is becoming an increasingly differentiated product. Among the many attributes that characterize yogurt, taste is one key attribute. As a result, yogurt manufacturers continuously introduce yogurt products with distinct tastes to the market. Besides the plain yogurt, yogurt also have a wide range of flavors, and the most common ones usually feature fruits or various combinations of fruits and grains. In addition, different levels of fat and sugar contents are also introduced in response to consumers' health concerns of overconsumption of fat and sugar. Furthermore, as some consumers become increasingly alert to food additives, several yogurt manufacturers offer 'natural' yogurt with minimum application of food additives.

Another important type of yogurt attribute is related to the health benefits of yogurt, as consumers' increasing health consciousness is one major factor driving the growth of yogurt consumption. The health benefits of yogurt mainly include supporting gut health, improving the immune system or general health, and it is largely related to the addition of probiotics. ${ }^{1}$ Accordingly, yogurt containing probiotics often carry health

\footnotetext{
${ }^{1}$ The common types of probiotics added by yogurt manufacturers include Lactobacillus acidophilus, Lactobacillus casei, and Bifidus, and some manufacturers may also develop their own probiotics. Studies generally support the health benefits in a lab setting, yet a larger dosage is needed to demonstrate these benefits in a clinical trial (Scourboutakos et al., 2017).
} 
claims. However, despite these health benefits, yogurt is not recognized as functional food in China. ${ }^{2}$ In addition, yogurt manufactures also employ other food fortification methods to appeal to consumers' demand for healthy food. For example, a variety of vitamin and DHA is often added to yogurt specifically designed for children. However, most yogurt products sold on the Chinese market are not certified organic, which indicates that Chinese consumers do not demonstrate sufficient attention to the organic attribute. This is in contrast to the U.S. and European yogurt market where consumers generally have positive willingness to pay for the organic attribute of yogurt (Bimbo et al., 2016; Bonanno, 2016).

Furthermore, the ambient yogurt is unique to the Chinese market, and it maintains the fastest growth among all types of yogurt (DaxueConsulting, 2019). Ambient yogurt is heat treated after fermentation - the fermentation process retains all the benefits of bacterial cultures, while the heat treatment enables the product to be stored at room temperature (ChrHansen, 2019). The popularity of ambient yogurt is closely linked to the convenience it brings to consumers, and the under-development of cold-chain infrastructure provides further momentum for yogurt producers to invest in ambient yogurt (DaxueConsulting, 2019). Besides product differentiation, yogurt manufacturers generally create many sub-brands with a variety of product positioning under their main brand to target different consumer segments. As an example, all three leading national brands have sub-brands for ambient yogurt (Bright Momchilovtsi, Yili Ambpoeial, and Mengniu Chunzhen). The competition in the yogurt market is not only at the brand (manufacturer) level, but also at the sub-brand level, especially among sub-brands with similar product positioning.

The yogurt market and demand for yogurt has attracted much research interests, and because yogurt is a differentiated product with numerous attributes and brands and sub-brands, several studies are aimed at examining the price premium of various yogurt attributes and brands. These studies are largely focused on the U.S. and European countries, in particular, Italy. Carlucci et al. (2013) offered one of the earliest analysis to investigate yogurt attributes on yogurt prices variability in Italy. Also in Italy, Bimbo et al. (2016) focused on the effects of health claims on yogurt prices, and they found the implicit prices associated with health claims differ across the types of health claims, efficacy and brands. Moreover, Bonanno (2016) investigated the roles of health and non-health attributes in yogurt prices in the U.S, and they find the presence of probiotics, specific health claims, and other credence attributes are valued positively.

Despite the strong growth of the yogurt market in China, no studies have examined consumers' valuation of yogurt attributes and brands in China. The objective of this article is to fill this research gap within the hedonic analysis framework. We contribute to the literature in twofold. First, we increase the understanding of what yogurt attributes Chinese consumers value. Findings from similar studies in other countries are not directly transferrable to the Chinese market because Chinese consumers may have distinct preference for yogurt attributes, and they may also value a different set of attributes. The estimated implicit price of yogurt attributes may help yogurt manufacturers operating in China to evaluate the effectiveness of introducing products with corresponding attributes. Second, although previous studies generally account for the effect of brand on yogurt price, i.e. brand equity, yet they largely ignore the role of sub-brands, which could reflect the unique product positioning of the sub-brand and its price premium, i.e. sub-brand equity. We specifically analyze the sub-brand equity in our analysis. Knowing how consumers value sub-brands help to better understand consumer's preference, and for yogurt manufacturers, this knowledge contributes to firms' product positioning and management of sub-brands.

The remainder of this article is organized as follows. Section 2 introduces the theory relevant to brand equity and sub-brand equity. Section 3 describes the data and Section 4 discusses the hedonic model and the econometric specifications. Section 5 presents results and discussions. Section 6 concludes.

\footnotetext{
${ }^{2}$ Companies producing functional food are required to apply and obtain the health food registration certificate, and few yogurt producers obtain
} the certificate. 


\section{Brand and sub-brand equity of yogurt}

Brand equity includes a series of brand assets - brand loyalty, brand awareness, perceived quality, brand associations, and other proprietary brand assets (Aaker, 1992). The source of brand equity has long been established in the marketing and economics literature. On the one hand, brand equity lies in consumers' awareness of brand features and associations, which drive attribute perceptions (Baltas and Saridakis, 2010), and brand value is the result of a strong, favorable and unique association in consumers' mind between brand name and product quality (Keller, 1993). On the other hand, brand value is related to the informational gain that one brand provides. As many markets are characterized by asymmetric information between consumers and producers, brand can convey the quality of products to potential consumers, substituting their time and skills in assessing product quality (Jin et al., 2008). In the context of yogurt market in China, brand further provides information regarding the food safety of the yogurt product. Though consumers still pay much attention to food safety, there is no explicit information for consumers to determine the safety of a yogurt product since all yogurt products legally sold on the market should be deemed to be safe by default. Therefore, consumers may rely on the brand to obtain more assurance that a yogurt product is safe to consume, and the brand equity includes the value of guaranteed food safety.

One way to improve brand equity is through marketing activities, and firms could employ numerous marketing tools to increase brand equity besides supplying high-quality products. Advertising, in particular, plays the central role in firms' marketing toolbox. Not only advertising is demonstrated to improve brand's own equity (Yoo et al., 2000), but also it can counteract the tendencies of brand loyalty of other brands by encouraging consumers to switch (Shum, 2004). As a result, almost all yogurt firms in China spend liberally on advertising with the aim of building a strong brand and increase brand equity. As of 2015, the total advertising expenditures of the three leading firms are 3.55, 7.28 and 4.09 billion yuan respectively, which were substantially larger than their profits. In particular, the advertising expenditure of Bright is 8.5 times of its net profits (HexunNews, 2016). However, the effectiveness of advertising in improving yogurt brand equity remains unknown, and further advertising and marketing campaigns depend on the knowledge of brand equity one manufacture has.

To measure brand equity, many methods have been proposed, yet it is best measured with price premium because any driver of brand equity should affect the price premium (Aaker, 1996). Numerous studies have evaluated the effect of brand using the hedonic analysis framework, and they largely confirmed the existence of brand equity. In particular, national brands tend to have higher price premium than private labels (see Szathvary and Trestini (2014) for fruit beverage in Italy, Bronnmann and Asche (2015) for frozen food in Germany, and Vickner (2015) for breakfast sausage in the U.S.).

Although brand can inform consumers of the quality and reliability, it may not convey specific information on product positioning. As a result, yogurt producers generally create sub-brands, each with different product positioning and targeting different segments of consumers, under their main brand. The product positioning reflected in the sub-brand identifies particular combinations of attributes to consumers from which consumers may benefit through reducing search cost and the uncertainty of purchasing poor quality products (Schulz et al., 2012). To certain degree, sub-brand assumes some roles of the main brand it belongs to, and it complements the main brand in providing a comprehensive information regarding product positioning to consumers. As an example, the sub-brand Bright Momchilovtsi first shows that this yogurt product is manufactured by a trustworthy national brand - Bright, but the brand name does not suggest the type of yogurt because Bright producers many different types of yogurt products under different sub-brands. This missing information is filled by the sub-brand name, Momchilovtsi, which signals to the Chinese yogurt consumers that it is of premium quality with high protein contents, and can be stored at room temperature. In conclusion, the sub-brand equity contains not only the brand equity, but also the value of different product positioning indicated by sub-brand equity. 
It needs to be noted that not all yogurt attributes can be quantified, and some intrinsic characteristics are embedded in the product positioning, e.g. the sourness and texture of yogurt. Thus, it is important to account for the sub-brand equity in hedonic analysis of yogurt prices. Furthermore, different manufacturers could have sub-brands with similar positioning on the market. The competition between these sub-brands with similar positioning could be more intense than between sub-brands with distinct positioning. This provides additional motivation to study sub-brand equity since this knowledge may direct yogurt manufacturers to distribute marketing resources efficiently among its sub-brands, given competition from similarly-positioned sub-brands manufactured by other brands.

\section{Data}

The main data source is the Kantar Worldpanel, provided by CTR Market Research in China. CTR maintains a representative panel of households in four major cities in China - Shanghai, Beijing, Guangzhou, and Shenzhen, and households in the panel are requested to keep a detailed record of their yogurt purchases from 2014 to 2015. For each yogurt product purchased, household records the purchasing location and time, total expenditure and total volume of each yogurt product, and product specifications. Unlike the scanner data commonly used in the U.S. and Europe, this data does not contain the universal product code (UPC). However, we are able to identify a majority of the yogurt purchased using product name, brand name, and the product specifications, and this allows us to include additional attributes in our analysis. Specifically, we search through the major online stores in China and yogurt manufacturers' websites and add the information whether one yogurt product contains probiotics in our dataset. ${ }^{3}$ Since more than $80 \%$ of yogurt is purchased in supermarkets and convenience stores in China, we include these purchases in our analysis. ${ }^{4}$ Also, to simplify our analysis, we focus on the largest ten brands nationwide, and these brands have a combined market share of over $90 \%$. Some of these large brands are local to a city or region, e.g. Sanyuan is mainly available in Beijing in our data though it is expanding rapidly to other cities.

Product specifications in our data include flavor, fat content, sugar content, storage condition, shelf life, main ingredients, and whether the product is made for children. Yogurt differs substantially in these respects. However, we do not directly use these product specifications to explain yogurt prices, and we define yogurt attributes based on these specifications. ${ }^{5}$ First, yogurt products generally contain a combination of fruits and grains besides the plain flavor; we define the flavor attribute as whether one yogurt product is plain flavored. Second, there are several levels of fat content and sugar content, and we define the fat and sugar attributes as having whole fat or having sugar, respectively. Moreover, we use the storage conditions and shelf life to infer whether a yogurt product is ambient since it has a long shelf life and can be stored at room temperature. The definitions of the explanatory variables are summarized in Table 1, and the attributes include all major yogurt attributes in the Chinese yogurt market.

\footnotetext{
${ }^{3}$ The online stores we visit are Taobao (Taobao.com) and JD (JD.com), both have a large number of yogurt products in their website. We do not distinguish different types of probiotics since most consumers may not have the ability to tell them apart, and yogurt producers generally do not emphasize the types of probiotics in the packaging.

${ }^{4}$ Some yogurt purchases are shown to be made in locations which do not usually sell yogurt, for example, wet markets and department stores, and we thus deem these observations to be unreliable possibly due to coding errors. Therefore, we only focus on purchase made in supermarkets and convenience stores.

${ }^{5}$ Many of these product specifications are categorical variables with numerous levels. If we use them directly in our analysis, little marketing implications can be drawn. For example, there are a large number of flavors, most of which takes a small proportion of the yogurt purchased. Thus, it would not be meaningful to compare price premium across flavors with very small market shares. One better approach, as adopted here, is to group similar flavors, and compare price differences between these major groups of flavors. Econometrically, we also avoid the problem of multicollinearity which hinders our statistical inference.
} 
Table 1. Explanatory variable description.

\begin{tabular}{lll}
\hline Variable & Description & Type \\
\hline Price & Price of yogurt in yuan $/ 100 \mathrm{~g}$ & continuous \\
Plain & Plain flavored $=1 ;$ otherwise $=0$ & dummy \\
Fat & Containing whole fat $=1 ;$ otherwise $=0$ & dummy \\
Sugar & Containing sugar $=1 ;$ otherwise $=0$ & dummy \\
Probiotics & Containing probiotics $=1 ;$ otherwise $=0$ & dummy \\
Ambient & Ambient $=1 ;$ otherwise $=0$ & dummy \\
Kid & Designed for kids $=1 ;$ otherwise $=0$ & dummy \\
Bright & Bright $=1 ;$ otherwise $=0$ & dummy \\
Yili & Yili $=1 ;$ otherwise $=0$ & dummy \\
Mengniu & Mengniu $=1 ;$ otherwise $=0$ & dummy \\
Danone & Danone $=1 ;$ otherwise $=0$ & dummy \\
Sanyuan & Sanyuan $=1 ;$ otherwise $=0$ & dummy \\
ClassyKiss & ClassyKiss $=1 ;$ otherwise $=0$ & dummy \\
Junlebao & Junlebao $=1 ;$ otherwise $=0$ & dummy \\
Xiangmanlou & Xiangmanlou $=1 ;$ otherwise $=0$ & dummy \\
Wandashan & Wandashan $=1 ;$ otherwise $=0$ & dummy \\
Weichuan & Weichuan $=1 ;$ otherwise $=0$ & dummy \\
\hline
\end{tabular}

The descriptive statistics of the attributes by city, and on the national level is shown in Table 2 . The average price for yogurt is calculated as total expenditure divided by total volume, and we also exclude purchases with extreme values of average prices. ${ }^{6}$ This leaves us a final sample of 98,453 observations. The average price of yogurt is 2.08 yuan/100 grams nationwide, and yogurt prices differ substantially across cities. Beijing in the north has the lowest average price of 1.93 yuan/100 grams whereas Guangzhou and Shenzhen in the south have the highest average prices of more than 2.2 yuan/100 grams. This pattern is consistent with the fact that most milk production is located in the north of China. Another notable feature is that most yogurt products purchased have whole fat and do not have reduced sugar, whereas yogurt products sold in other countries often have low fat and sugar contents (Bonanno, 2016). Containing probiotics seems to be an important attribute to consumers since more than $65 \%$ of yogurt products purchased contain some varieties of probiotics. Lastly, spatial differences in yogurt attributes supports heterogenous preference for yogurt across cities.

The lower half of Table 2 shows the market shares of different brands of yogurt in each city. The preference for Bright is evident in Shanghai since it accounts for half of the products sold there. This could be attributed to the preference for local brands in the city. In Beijing, however, the yogurt market is dominated by the national brands Yili and Mengniu, and the local brand Sanyuan. By contrast, in Guangzhou, local brands and international brands have the majority shares with Classy Kiss, Xiangmanlou, and Danone leading the market. In Shenzhen, the national brands Yili, and Mengniu, and the local brand Classy Kiss sharing the majority of market shares.

\footnotetext{
${ }^{6}$ Extreme prices are those below the $1 \%$ percentile or above the $99 \%$ percentile in the distribution of average price.
} 
Table 2. Mean values (SD) of yogurt attributes and market shares of brands by city. ${ }^{1}$

\begin{tabular}{|c|c|c|c|c|c|}
\hline & Shanghai & Beijing & Guangzhou & Shenzhen & National \\
\hline \multicolumn{6}{|l|}{ Attribute } \\
\hline \multirow[t]{2}{*}{ Price } & 2.133 & 1.936 & 2.250 & 2.269 & 2.081 \\
\hline & $(0.734)$ & $(0.759)$ & $(0.918)$ & $(0.937)$ & $(0.809)$ \\
\hline \multirow[t]{2}{*}{ Plain } & 0.733 & 0.574 & 0.663 & 0.597 & 0.642 \\
\hline & $(0.443)$ & $(0.494)$ & $(0.473)$ & $(0.490)$ & $(0.479)$ \\
\hline \multirow[t]{2}{*}{ Fat } & 0.794 & 0.958 & 0.899 & 0.975 & 0.897 \\
\hline & $(0.405)$ & $(0.201)$ & $(0.302)$ & $(0.157)$ & $(0.304)$ \\
\hline \multirow[t]{2}{*}{ Sugar } & 0.983 & 0.941 & 0.997 & 0.998 & 0.969 \\
\hline & $(0.130)$ & $(0.235)$ & $(0.055)$ & $(0.040)$ & $(0.174)$ \\
\hline \multirow[t]{2}{*}{ Probiotics } & 0.838 & 0.424 & 0.831 & 0.716 & 0.650 \\
\hline & $(0.368)$ & $(0.494)$ & $(0.375)$ & $(0.451)$ & $(0.477)$ \\
\hline \multirow[t]{2}{*}{ Ambient } & 0.175 & 0.033 & 0.028 & 0.103 & 0.082 \\
\hline & $(0.380)$ & $(0.179)$ & $(0.165)$ & $(0.304)$ & $(0.274)$ \\
\hline \multirow[t]{2}{*}{ Kid } & 0.028 & 0.054 & 0.017 & 0.016 & 0.036 \\
\hline & $(0.166)$ & $(0.227)$ & $(0.128)$ & $(0.125)$ & $(0.187)$ \\
\hline \multicolumn{6}{|l|}{ Brand } \\
\hline \multirow[t]{2}{*}{ Bright } & 0.500 & 0.089 & 0.347 & 0.349 & 0.285 \\
\hline & $(0.500)$ & $(0.284)$ & $(0.476)$ & $(0.477)$ & $(0.451)$ \\
\hline \multirow[t]{2}{*}{ Yili } & 0.100 & 0.320 & 0.065 & 0.165 & 0.193 \\
\hline & $(0.301)$ & $(0.466)$ & $(0.247)$ & $(0.371)$ & $(0.394)$ \\
\hline \multirow[t]{2}{*}{ Mengniu } & 0.077 & 0.212 & 0.058 & 0.188 & 0.140 \\
\hline & $(0.267)$ & $(0.409)$ & $(0.233)$ & $(0.390)$ & $(0.346)$ \\
\hline \multirow[t]{2}{*}{ Danone } & 0.282 & 0.008 & 0.196 & 0.027 & 0.129 \\
\hline & $(0.450)$ & $(0.090)$ & $(0.397)$ & $(0.163)$ & $(0.336)$ \\
\hline \multirow[t]{2}{*}{ Sanyuan } & & 0.217 & & & 0.093 \\
\hline & & $(0.412)$ & & & $(0.290)$ \\
\hline \multirow[t]{2}{*}{ ClassyKiss } & 0.000 & & 0.199 & 0.233 & 0.055 \\
\hline & $(0.014)$ & & $(0.399)$ & $(0.423)$ & $(0.227)$ \\
\hline \multirow[t]{2}{*}{ Junlebao } & 0.000 & 0.085 & & 0.000 & 0.036 \\
\hline & $(0.014)$ & $(0.278)$ & & $(0.012)$ & $(0.187)$ \\
\hline \multirow[t]{2}{*}{ Xiangmanlou } & & & 0.135 & 0.038 & 0.028 \\
\hline & & & $(0.341)$ & $(0.190)$ & $(0.164)$ \\
\hline \multirow[t]{2}{*}{ Wandashan } & 0.000 & 0.063 & & & 0.027 \\
\hline & $(0.006)$ & $(0.243)$ & & & $(0.162)$ \\
\hline \multirow[t]{2}{*}{ Weichuan } & 0.040 & 0.006 & 0.001 & & 0.015 \\
\hline & $(0.196)$ & $(0.080)$ & $(0.025)$ & & $(0.123)$ \\
\hline $\mathrm{n}$ & 30,672 & 42,099 & 18,217 & 7,465 & 98,453 \\
\hline
\end{tabular}

${ }^{1}$ Standard deviations in parentheses.

\section{Hedonic model}

Lancaster (1966) developed a theory of consumer demand in which consumer derive utility from the properties or characteristics of a good rather the good itself, and consumption can be assumed as an activity in which goods are inputs, and a collection of characteristics are outputs. This suggests that a product can be viewed as a combination of its attributes. Based on this, Rosen (1974) formalized the hedonic price theory using a spatial equilibrium model in which the locational decisions of consumers and producers in the characteristic space are guided by the implicit prices of these characteristics. Specifically, he defined a bid function which captures a consumer's willing to pay for a good with a set of attributes $z$ from consumer's utility maximization 
problem, and an offer function which captures a firm's willing to sell for the good with attributes $z$ from firm's profit maximization problem. If a market transaction is observed for this good with attributes $z$ at price $p$, the marginal bid equals to the marginal offer for all attributes in $z$, and the observed price $p$ can be expressed as a function of $z$, such that

$$
p=f\left(z_{1} \ldots z_{k}\right)
$$

The implicit price associated with each attribute $z_{i}$ can be estimated with regression technique.

We use the log-linear functional form in our hedonic function for yogurt since it is the most widely used functional from in the hedonic analysis (Costanigro et al., 2011), and the basic hedonic model takes the following form

$$
\begin{aligned}
\log \left(p_{i c w}\right)=\beta_{0} & +\sum_{a=1}^{6} \beta_{1 a} \text { attribute }_{a}+\sum_{b=2}^{10} \gamma_{2 b} \text { brand }_{b} \\
& +\sum_{o=2}^{10} \delta_{3 o} \text { outlet }_{o}+\sum_{c=2}^{4} \zeta_{4 c} \text { city }_{c}+\sum_{w=2}^{104} \eta_{5 w} \text { week }_{w}+\epsilon_{i c w}
\end{aligned}
$$

where $i$ indicates a yogurt product, $c$ indicates city, and $w$ indicates week. attribute ${ }_{a}$ is a vector of yogurt attributes as we discussed in the previous section, and brand $_{b}$ is a vector containing the brand dummies of the largest ten yogurt brands. outlet $_{o}$, city ${ }_{m}$ and week ${ }_{t}$ are vectors of dummies representing different outlet, city and week, respectively. $\epsilon_{i c w}$ is the error term. As discussed above, we include the brand dummies to estimate the brand equity associated with each brand. ${ }^{7}$ Moreover, it is plausible that the pricing of yogurt may differ across outlets due to their pricing strategies, even for the same product, and yogurt prices may also fluctuate over time and differ across cities because of the pricing strategies adopted by sellers or because of the spatial and temporal factors affecting milk demand and supply, we control for the fixed effect at the levels of outlet, city and week in our models. In addition, unobserved factors affecting yogurt prices may differ across brands and regions, and some of these factors may also have persistent impact on yogurt prices, which could lead to heterogeneity and autocorrelation in the error term. To deal with this issue, we calculate the robust standard errors for the estimated coefficients.

Another complication is that consumer preference for yogurt attributes and brands may vary across cities, and we introduce the interaction between yogurt attributes and city, and between brand dummies and city to allow differing price premiums for yogurt attributes and brands across cities, and the model takes the following form

$$
\begin{aligned}
\log \left(p_{i c w}\right)=\beta_{0} & +\sum_{a=1}^{6} \beta_{1 a} \text { attribute }_{a}+\sum_{b=2}^{10} \gamma_{2 b} \text { brand }_{b} \\
& +\sum_{c=2}^{4} \sum_{a=1}^{6} \theta_{c a} \text { attribute }_{a} * \text { city }_{c} \\
& +\sum_{c=2}^{4} \sum_{b=2}^{10} \rho_{c b} \text { brand }_{b} * \text { city }_{c}+\sum_{o=2}^{10} \delta_{3 o} \text { outlet }_{o} \\
& +\sum_{c=2}^{4} \zeta_{4 c} \text { city }_{c}+\sum_{w=2}^{104} \eta_{5 w} \text { wee }_{w}+\epsilon_{i c w} .
\end{aligned}
$$

With this specification, preference heterogeneity across cities can be formally tested using F-test and the null hypothesis is the interaction terms between attribute/brand and city are jointly zero, i.e. $\theta_{2 \mathrm{a}}=\theta_{3 \mathrm{a}}=\theta_{4 \mathrm{a}}=0$ and $\rho_{2 \mathrm{a}}=\rho_{3 \mathrm{a}}=\rho_{4 \mathrm{a}}=0$. It needs to be noted, however, that the estimated coefficients cannot be interpreted as price premium due to the interaction terms; we take the derivative with respect to each attribute and brand variable, and calculate the price premium of each attribute/brand for each city. The standard errors of these price premiums are calculated using the delta method.

\footnotetext{
7 The coefficients of the brand dummies, i.e. price premium of brand calculated from the hedonic regression may also contain other intrinsic characteristics associated with the brand, such as sourness and texture of yogurt.
} 
Moreover, as we discussed above, each sub-brand could have distinct price premium due to different sub-brand positioning, even within the same brand. To examine the price premium associated with each subbrand, i.e. the sub-brand equity while accounting for heterogenous preference across cities, one may extend the previous model by introducing the interaction between sub-brand and city dummies. However, given the large number of sub-brands offered by yogurt producers in our data, this approach is cumbersome and intractable. One workaround is to split the sample by city and estimate the hedonic model with sub-brand fixed effect controlled in each city. We adopt this approach, and, as comparison, we also estimate hedonic models with brand fixed effect controlled for each city. It needs to be noted that yogurt manufacturers generally dedicated some sub-brands for ambient yogurt or yogurt designed specifically for children, which results perfect correlation between these two attributes and the sub-brand fixed effects. To avoid this multicollinearity problem, we omit the two attributes in the city-specific hedonic estimation. By comparing the two models, we further evaluate the additional contribution of sub-brand equity in explaining yogurt price variation, and the relative explanatory power of yogurt attributes and brand across cities. All models are estimated with Stata 14.2 (StataCorp LLC, College Station, TX, USA).

\section{Results and discussion}

The main results of the hedonic regressions are shown in Table 3, and in both model specifications, we control for the fixed effect at the levels of outlet, city and week. Overall, the performance of the model is satisfactory. As shown in Model 1, yogurt attributes included in the analysis, together with factors related to outlet, city and week, explain $30.5 \%$ of the total variation in yogurt price. In addition, yogurt brands contribute to additional $12.9 \%$ of the price variation, which gives the first clue of the role of brand equity in explaining consumers' valuation of yogurt. The null hypotheses of no preference heterogeneity across cities are rejected for all attributes and brand dummies, as shown by the F-tests in the last column of Table 3. Hence, the direct implication follows is that yogurt producers operating in China need to account for the regional differences in consumers' preference for yogurt attributes and brands, and their product strategies, brand strategies, and marketing campaigns should be city-specific.

\subsection{Price premium of yogurt attributes}

The price premium associated with each attribute and brand in each city are shown in Table 4. Comparing with flavored yogurt, the average price of plain yogurt is lower by around 20\% in Shanghai, Beijing and Guangzhou, while in Shenzhen, this number is around 11.2\%. Moreover, yogurt with whole fat has a price premium between 8.9 and $24.9 \%$ on average, whereas yogurt with sugar generally have a price discount albeit this discount is insignificant in Shenzhen. These results characterize Chinese consumers' ideal taste for yogurt - being flavored with whole-fat adds to the desirableness of the yogurt product while having sugar does not. This seemingly contradictory result may reflect Chinese consumers' awareness of a healthy diet. While fat may still be safe to consume, sugar consumption could present a threat to health, although this notion also varies across cities. This result provides additional support for yogurt manufacturers in China to follow a global trend in reducing sugar consumption, and developing low-sugar yogurt products should be one important strategy to attract health-conscious consumers.

Moreover, having probiotics has a range of price premium between $8.7 \%$ in Guangzhou and 36.8\% in Beijing. This result highlights one important aspect in which yogurt firms can differentiate their products. As Chinese consumers pay more attention to a healthy diet, yogurt manufacturers could increase value to their products by adding probiotics in their yogurt products. As a result, investing in different types of probiotics with more health benefits could be an important product strategy. Furthermore, ambient yogurt has a price premium of between 30 and $40 \%$ across all cities, which suggests that the convenience brought by ambient yogurt is highly valued in China. For yogurt manufacturers, the development of ambient yogurt could further reduce the marketing costs given that cold chain logistics is not needed in distributing ambient yogurt. Lastly, the price premium of yogurt specifically designed for children ranges from $5.5 \%$ in Shanghai and $49 \%$ in Shenzhen. These results are qualitatively consistent with previous findings from other countries (Bimbo et 
Table 3. Hedonic regression result. ${ }^{1}$

\begin{tabular}{|c|c|c|c|}
\hline & Model $1^{2}$ & Model $2^{2}$ & F-stat ${ }^{3}$ \\
\hline \multirow[t]{2}{*}{ Plain } & $-0.311^{* * *}$ & $-0.286^{* * *}$ & 128.19 \\
\hline & $(0.004)$ & $(0.004)$ & $(0.000)$ \\
\hline \multirow[t]{2}{*}{ Fat } & $0.087^{* * *}$ & $0.137^{* * *}$ & 97.68 \\
\hline & $(0.004)$ & $(0.005)$ & $(0.000)$ \\
\hline \multirow[t]{2}{*}{ Sugar } & $-0.071^{* * *}$ & $-0.094^{* * *}$ & 24.14 \\
\hline & $(0.009)$ & $(0.009)$ & $(0.000)$ \\
\hline \multirow[t]{2}{*}{ Probiotics } & $0.159^{* * *}$ & $0.164^{* * *}$ & 499.28 \\
\hline & $(0.005)$ & $(0.006)$ & $(0.000)$ \\
\hline \multirow[t]{2}{*}{ Ambient } & $0.323^{* * *}$ & $0.322^{* * *}$ & 27.88 \\
\hline & $(0.004)$ & $(0.004)$ & $(0.000)$ \\
\hline \multirow[t]{2}{*}{ Kid } & $0.052^{* * *}$ & $0.055^{* * *}$ & 237.05 \\
\hline & $(0.011)$ & $(0.011)$ & $(0.000)$ \\
\hline \multirow[t]{2}{*}{ Bright } & & $0.092 * * *$ & 436.76 \\
\hline & & $(0.007)$ & $(0.000)$ \\
\hline \multirow[t]{2}{*}{ Yili } & & $0.133 * * *$ & 55.90 \\
\hline & & $(0.008)$ & $(0.000)$ \\
\hline \multicolumn{4}{|l|}{ Mengniu } \\
\hline \multirow[t]{2}{*}{ Danone } & & $0.111 * * *$ & 27.84 \\
\hline & & $(0.007)$ & $(0.000)$ \\
\hline \multirow[t]{2}{*}{ Sanyuan } & & $0.090 * * *$ & \\
\hline & & $(0.005)$ & \\
\hline \multirow[t]{2}{*}{ ClassyKiss } & & $0.724 * * *$ & 6.96 \\
\hline & & $(0.077)$ & $(0.001)$ \\
\hline \multirow[t]{2}{*}{ Junlebao } & & 0.111 & 293.50 \\
\hline & & $(0.123)$ & $(0.000)$ \\
\hline \multirow[t]{2}{*}{ Xiangmanlou } & & $-0.167 * * *$ & 0.71 \\
\hline & & $(0.019)$ & $(0.401)$ \\
\hline \multirow[t]{2}{*}{ Wandashan } & & $-0.091 * * *$ & 100.40 \\
\hline & & $(0.013)$ & $(0.000)$ \\
\hline \multirow[t]{2}{*}{ Weichuan } & & $0.317 * * *$ & 216.17 \\
\hline & & $(0.011)$ & $(0.000)$ \\
\hline \multirow[t]{2}{*}{ Constant } & $0.896^{* * *}$ & $0.785^{* * *}$ & \\
\hline & $(0.024)$ & $(0.024)$ & \\
\hline $\mathrm{n}$ & 98,453 & 98,453 & \\
\hline$R^{2}$ & 0.305 & 0.434 & \\
\hline adj. $R^{2}$ & 0.303 & 0.432 & \\
\hline
\end{tabular}

al., 2016, Bonanno, 2016, Carlucci et al., 2013). To conclude, adding probiotics, producing ambient yogurt, and designing yogurt specifically for children are effective product differentiation strategies for yogurt manufacturers operating in China. One caveat, however, is that yogurt producers also need to account for the production and development cost of producing yogurt with these new attributes. 
Table 4. Price premium for yogurt attributes and brands by city. ${ }^{1}$

\begin{tabular}{|c|c|c|c|c|}
\hline & Shanghai & Beijing & Guangzhou & Shenzhen \\
\hline \multicolumn{5}{|l|}{ Attribute } \\
\hline \multirow[t]{2}{*}{ Plain } & $-0.286^{* * *}$ & $-0.208^{* * *}$ & $-0.233^{* * *}$ & $-0.112^{* * *}$ \\
\hline & $(0.004)$ & $(0.003)$ & $(0.005)$ & $(0.009)$ \\
\hline \multirow[t]{2}{*}{ Fat } & $0.137^{* * *}$ & $0.089^{* * *}$ & $0.249^{* * *}$ & $0.089^{* * *}$ \\
\hline & $(0.005)$ & $(0.006)$ & $(0.007)$ & $(0.021)$ \\
\hline \multirow[t]{2}{*}{ Sugar } & $-0.094^{* * *}$ & $-0.036^{* * *}$ & $-0.293^{* * *}$ & -0.118 \\
\hline & $(0.009)$ & $(0.005)$ & $(0.039)$ & $(0.063)$ \\
\hline \multirow[t]{2}{*}{ Probiotics } & $0.164^{* * *}$ & $0.368^{* * *}$ & $0.087^{* * *}$ & $0.130^{* * *}$ \\
\hline & $(0.006)$ & $(0.004)$ & $(0.008)$ & $(0.017)$ \\
\hline \multirow[t]{2}{*}{ Ambient } & $0.322^{* * *}$ & $0.380^{* * *}$ & $0.372^{* * *}$ & $0.402^{* * *}$ \\
\hline & $(0.004)$ & $(0.009)$ & $(0.011)$ & $(0.011)$ \\
\hline \multirow[t]{2}{*}{ Kid } & $0.055^{* * *}$ & $0.354^{* * *}$ & $0.350^{* * *}$ & $0.490^{* * *}$ \\
\hline & $(0.011)$ & $(0.005)$ & $(0.013)$ & $(0.022)$ \\
\hline \multicolumn{5}{|l|}{ Brand } \\
\hline \multirow[t]{2}{*}{ Bright } & $0.092^{* * *}$ & $-0.238^{* * *}$ & $-0.041^{* *}$ & $-0.069^{* * *}$ \\
\hline & $(0.007)$ & $(0.006)$ & $(0.014)$ & $(0.015)$ \\
\hline \multirow[t]{2}{*}{ Yili } & $0.133^{* * *}$ & $0.055^{* * *}$ & $-0.043^{* *}$ & $-0.033^{*}$ \\
\hline & $(0.008)$ & $(0.004)$ & $(0.016)$ & $(0.015)$ \\
\hline \multirow[t]{2}{*}{ Danone } & $0.111^{* * *}$ & -0.022 & $0.153^{* * *}$ & $0.106^{* * *}$ \\
\hline & $(0.007)$ & $(0.015)$ & $(0.014)$ & $(0.026)$ \\
\hline \multirow[t]{2}{*}{ Sanyuan } & & $0.090^{* * *}$ & & \\
\hline & & $(0.005)$ & & \\
\hline \multirow[t]{2}{*}{ ClassyKiss } & $0.724^{* * *}$ & & $0.479^{* * *}$ & $0.530^{* * *}$ \\
\hline & $(0.077)$ & & $(0.015)$ & $(0.016)$ \\
\hline \multirow[t]{2}{*}{ Junlebao } & 0.111 & $-0.339^{* * *}$ & & $0.059^{* * *}$ \\
\hline & $(0.123)$ & $(0.007)$ & & $(0.015)$ \\
\hline \multirow[t]{2}{*}{ Xiangmanlou } & & & $-0.147^{* * *}$ & $-0.167^{* * *}$ \\
\hline & & & $(0.015)$ & $(0.019)$ \\
\hline \multirow[t]{2}{*}{ Wandashan } & $-0.091^{* * *}$ & $0.063^{* * *}$ & & \\
\hline & $(0.013)$ & $(0.009)$ & & \\
\hline \multirow[t]{2}{*}{ Weichuan } & $0.317^{* * *}$ & $0.317^{* * *}$ & $0.317^{* * *}$ & \\
\hline & $(0.011)$ & $(0.011)$ & $(0.011)$ & \\
\hline
\end{tabular}

\subsection{Brand and sub-brand equity of yogurt}

We continue to examine the brand and sub-brand equity of the ten largest brands on the Chinese market. A similar heterogeneity is also found for preference of yogurt brand across cities, as all F-tests reject the null hypotheses that the brand equity are identical across cities. We use Mengniu as the base brand due to its availability in all four cities, and the brand equities are shown in the lower panel of Table 4. The estimated brand equity demonstrates a clear geographical pattern. Comparing with Mengniu, Bright only shows a price premium in Shanghai $(9.2 \%)$, where it is a local brand, while in the other three cities, it has negative price premium. Moreover, Yili has a higher brand premium than Mengniu in Beijing and Shanghai (13.3 and 5.5\% respectively), whereas in Guangzhou and Shenzhen, its brand premium is lower (-4.3 and -3.3\% respectively). Furthermore, Danone enjoys a higher brand premium in all cities except Beijing comparing with Mengniu. These results suggest that the marketing strategies of the national brands should be cityspecific since they have different brand equity across cities. Specifically, given the increasing advertising expenditure by the entire dairy industry, yogurt firms may need to optimize their distribution of advertising 
and marketing resources across cities since the effectiveness of one marketing campaign depends on the existing brand equity one firm already has and the brand equity of other competitors. For example, Yili may focus its advertising more in Guangzhou and Shenzhen, where it has a lower brand equity.

The remaining brands are not available in all cities, and to simplify the discussion, we refer to these brands as local brands. Given the popularity of local food around the world in recent years (Schulz et al., 2012), we are mainly interested in examining whether local brands in a city or region would enjoy higher price premiums over the national Mengniu serving as the base brand. The results are mixed, however. On one hand, Xiangmanlou, which is local to Guangzhou, has lower brand equity. On the other hand, Sanyuan, a local brand in Beijing, and Classy Kiss, a local brand in Shenzhen, have higher brand equities than Mengniu in their origin cities (and other cities where they are available). High brand equity implies strong preference for the brand, which could further suggest that the marketing campaigns of competing firms may not be as effective. Also, the high brand equity enjoyed by the incumbent firms in one city may present as an entry barrier for other companies. As a result, yogurt producers expanding to cities with strong local brands, such as Beijing and Shenzhen, may need to account for the brand equity of firms already on the market when making production and marketing plans.

The results of the city-specific hedonic regressions with brand and sub-brand fixed effects are shown in Table 5. In all cities, the statistical fit of the hedonic model indicated by $\mathrm{R}^{2}$ has substantially improved with subbrand fixed effect controlled. The increasing explanatory power demonstrates that sub-brand equity plays a key role in consumers' valuation of yogurt, and besides the perceived quality of the parent brand, product positioning embedded in the sub-brand also affect consumers' valuation of yogurt products. Therefore, for yogurt manufacturers, while it is essential to maintain a strong brand and improve brand equity through advertising and other marketing activities, it is also important to build strong sub-brand with careful product positioning that caters to consumers' diverse need for yogurt. Quantitatively, the increase of $\mathrm{R}^{2}$ ranges from $15 \%$ in Guangzhou, and 30\% in Shanghai, which also indicates that the effect of sub-brand on consumers' valuation of yogurt differs across cities. In particular, consumers in Shanghai may value sub-brand more than in Guangzhou, and one implication for yogurt manufacturers is that developing sub-brands which satisfy consumers with diverse needs is relatively more important in Shanghai, while investing in marketing activities to improve the brand equity may be a priority in Guangzhou.

We continue to examine the sub-brand equity, and due to the large number of sub-brands available, the subbrand equities are plotted in Figure 1 to 4 for each city respectively. ${ }^{8}$ We use the Mengniu Guanyiru as the base due to its wide availability. One notable feature is that sub-brand equity varies substantially within a brand and also across brands. First, some sub-brands have high price premium while others may have low or even negative price premium comparing with the base, and the differences in sub-brand equity within the same brand can be mainly attributed to sub-brand's different product positioning since all sub-brands with a same brand would have the brand equity of the parent brand. Although it differs across cities, subbrands with high price premium generally have the following product positioning: natural yogurt (Rushi, and Purjoy), ambient yogurt (Momchilovtsi, Ambpoeial, Chunzhen, and Kefir), European-style yogurt (Pure Day), traditional style yogurt (1911, Mengniu Traditional), yogurt with high contents of fruits and grains (Guwu, Daguoli, Daguokuai, Daguoli, Siji Xianxuan, Wugu Yike, and Guoli,), and yogurt for children (QQ, and Weilaixing). It is clear that flavor is the central theme of product positioning for these sub-brands with high price premiums. These findings may guide yogurt manufactures in designing new products with more appealing flavors to consumers.

\footnotetext{
${ }^{8}$ Calculated sub-brand equities are provided in Supplementary Table S1.
} 


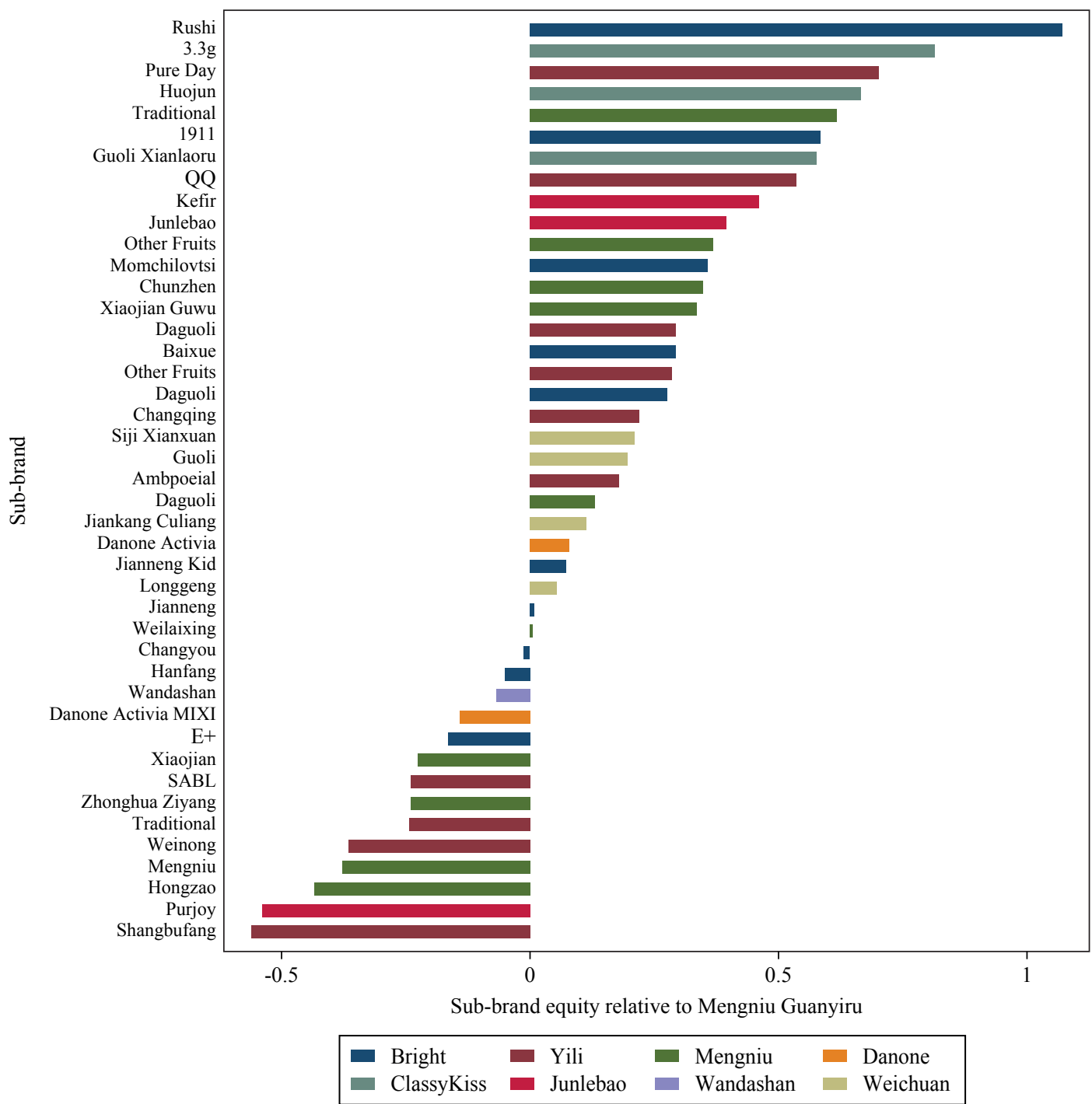

Figure 1. Sub-brand equity relative to Mengniu Guanyiru in Shanghai.

In addition, for the similarly positioned sub-brands, the sub-brand equity can also vary widely. This can be attributed to the differing price premium of the parent brand. For example, Bright Momchilovtsi, Yili Ambpoeial, and Mengniu Chunzhen are all ambient yogurt as we mentioned above. Except in Shanghai, Yili Ambpoeial has the highest sub-brand equity, followed by Bright Momchilovtsi, and Mengniu Chunzhen. This finding is generally consistent with the overall brand equity of the three leading national brands in the Chinese yogurt market. Lastly, not all sub-brands within the national brands have price premiums over sub-brands from local brands despite the brand equity, and this finding again highlights the importance of product positioning embodied in sub-brand. Therefore, the direct marketing implication of our findings is that yogurt producers may further investigate consumers' preference for yogurt, and position sub-brands which best meet consumer need. 


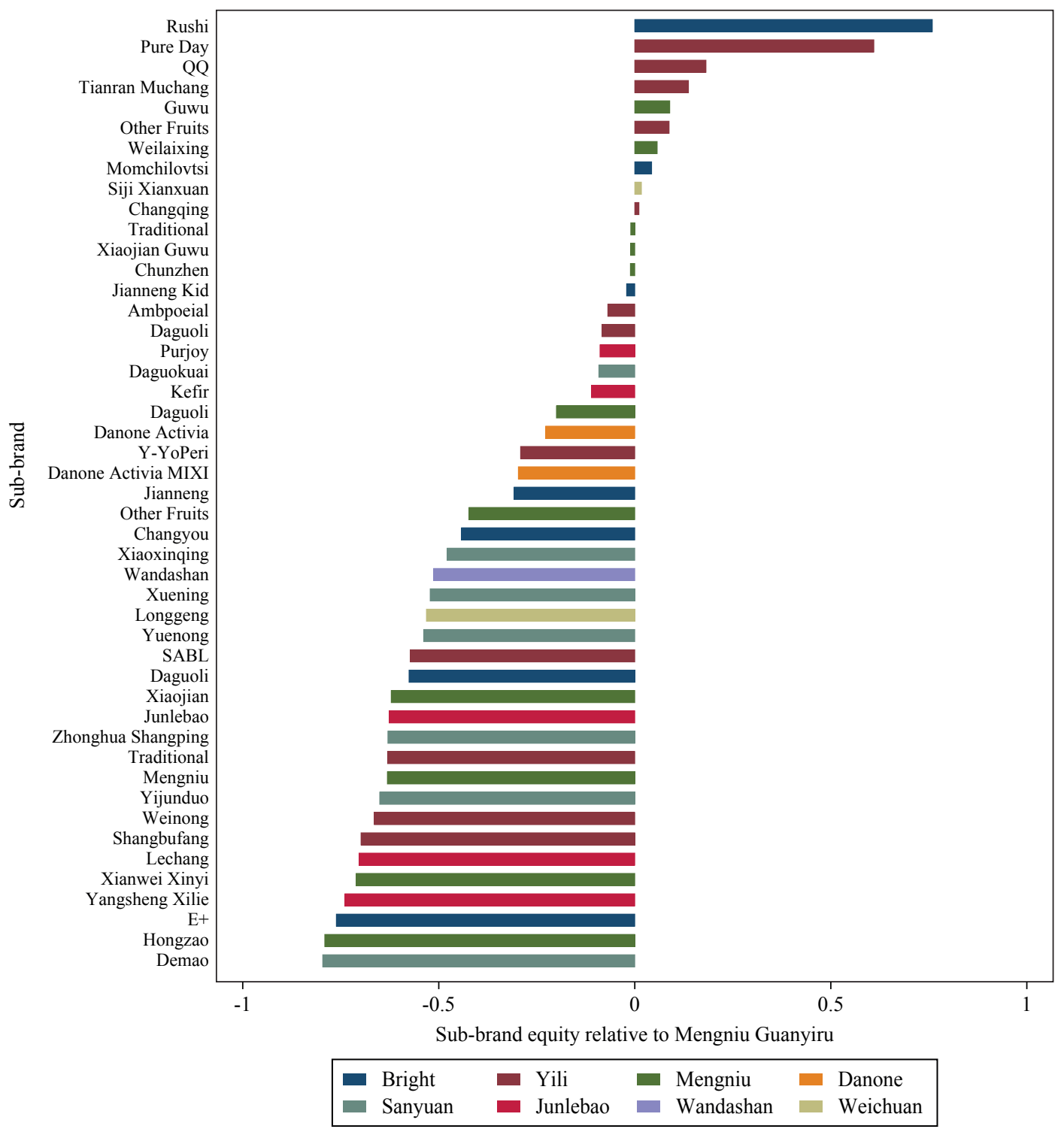

Figure 2. Sub-brand equity relative to Mengniu Guanyiru in Beijing. 


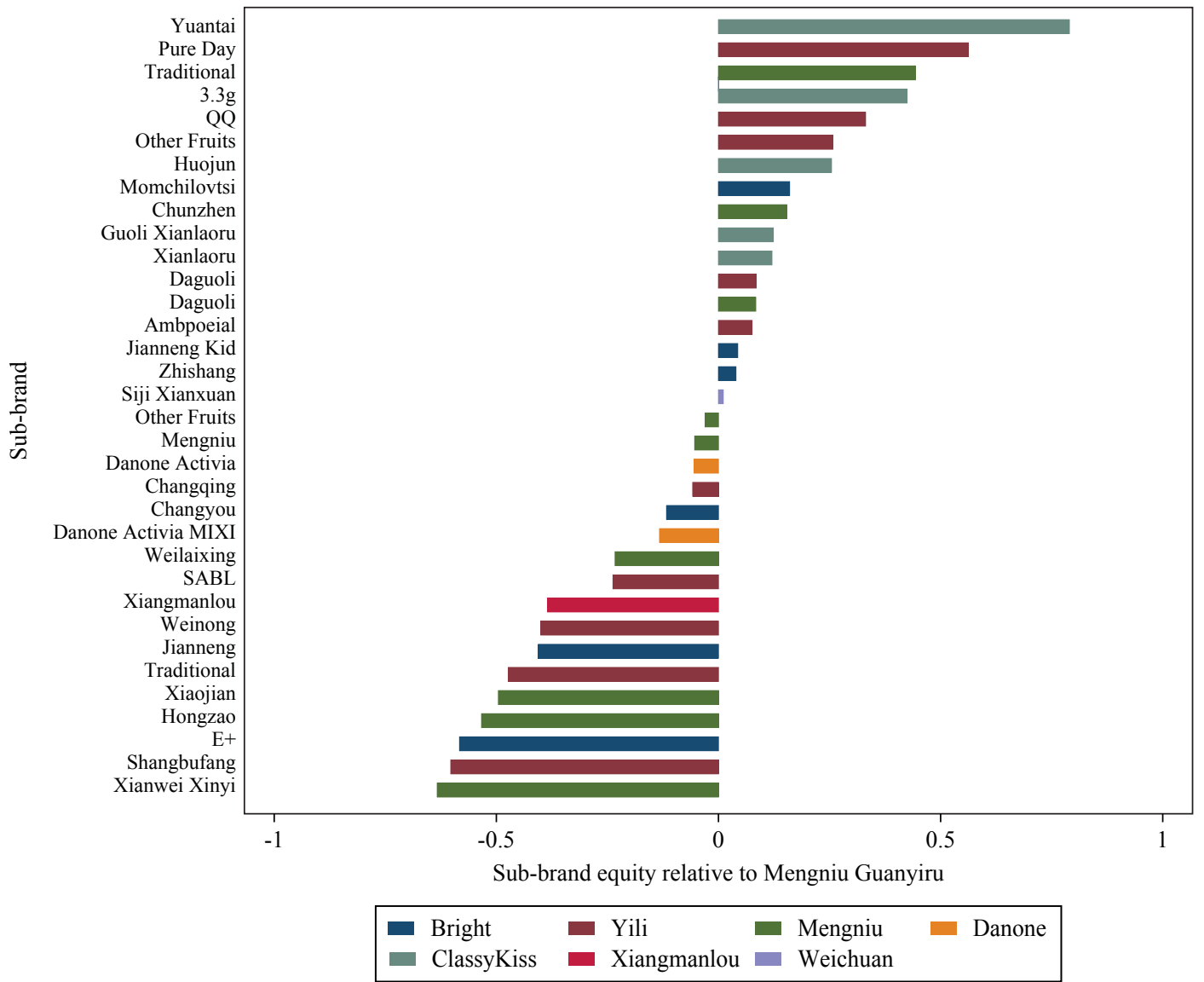

Figure 3. Sub-brand equity relative to Mengniu Guanyiru in Guangzhou.

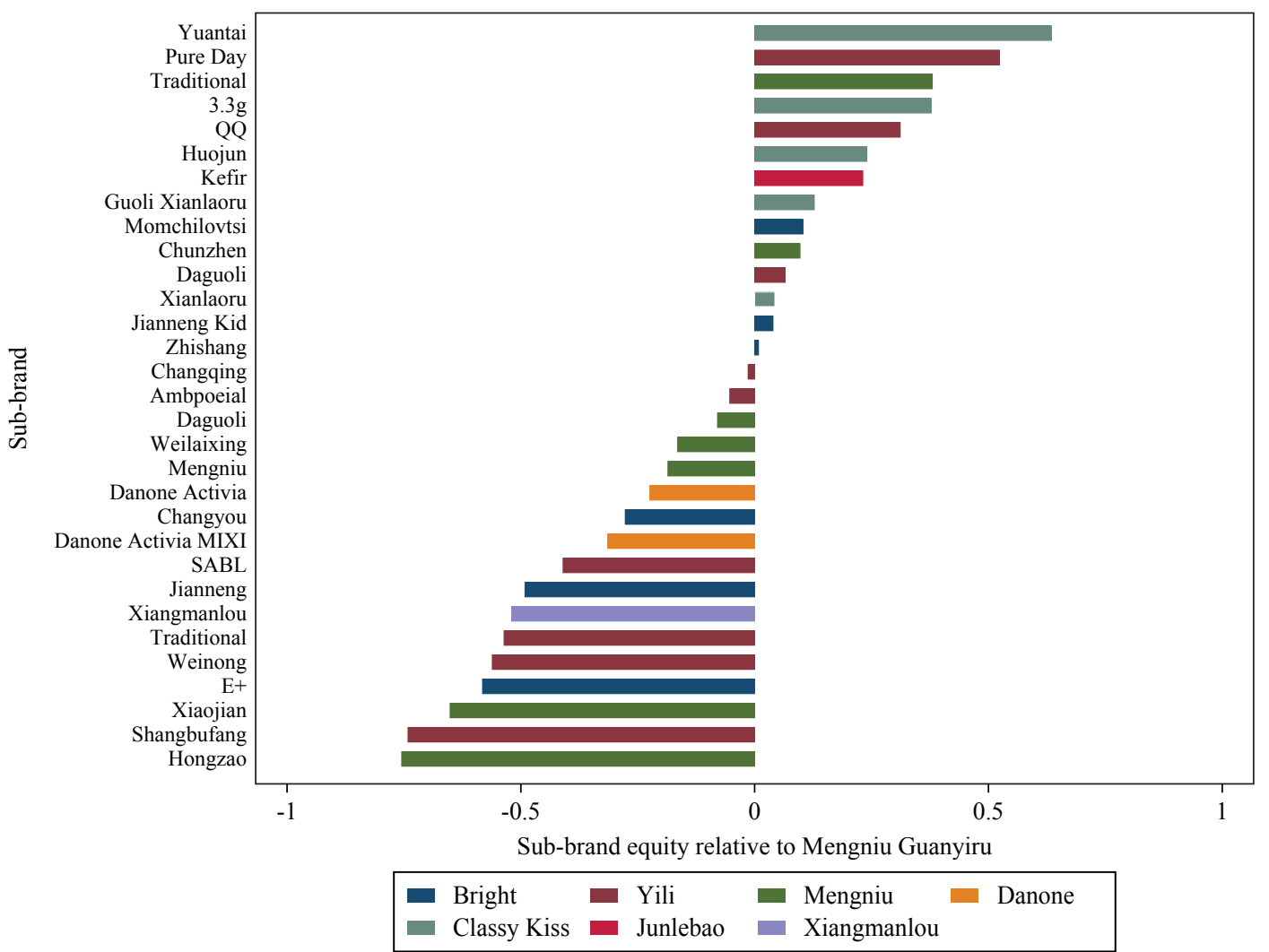

Figure 4. Sub-brand equity relative to Mengniu Guanyiru in Shenzhen. 
Table 5. Hedonic regression result by city. ${ }^{1}$

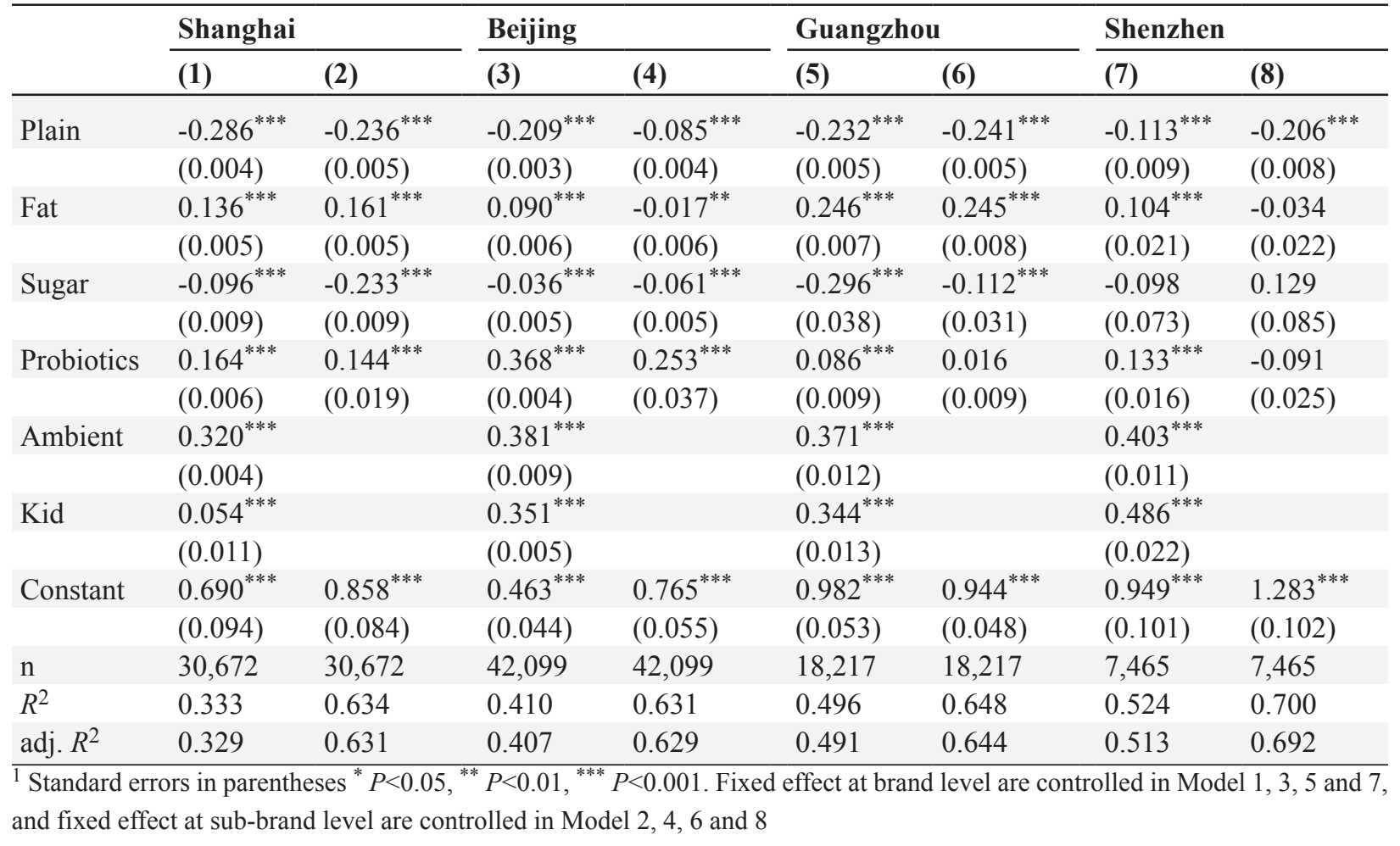

\section{Conclusions}

The yogurt market in China has experienced strong growth in recent years. To meet consumers' diverse demand, yogurt manufacturers employ a wide range of product differentiation strategies, and yogurt with distinct product positioning is often supplied under different sub-brands. In this article, we examine consumers' valuation of yogurt attributes and brands with a hedonic analysis framework. In particular, we account for the role of sub-brand in yogurt price, and investigate the sub-brand equity associated with each sub-brand.

Our main findings are that attributes of being plain flavored, and having sugar have negative price premiums, whereas the attributes of having fat, having probiotics, being ambient, and being designed for kids have positive price premiums. The price premiums, however, are different across cities, and yogurt manufacturers may use this information facilitate cost-benefit analysis of providing certain attributes. Moreover, we also find distinct brand equity measured by price premium associated with yogurt brands. For the three national brands, Bright only enjoys price premium in Shanghai, comparing with Mengniu. Yili has higher brand equity than Mengniu in Shanghai and Beijing, while Mengniu has higher brand equity than Yili in Guangzhou and Shenzhen. Also, comparing with the national brands, local brands do not necessarily command price premiums even in their origin cities, and our results only partially support preference for local brands in some cities.

Further, we find the price premium associated with the sub-brand, i.e. sub-brand equity, varies substantially within a brand and across brands. There is also considerable heterogeneity in sub-brand equity across cities. Importantly, sub-brands that position themselves as ambient yogurt, European-style yogurt, natural yogurt, traditional style yogurt, yogurt with high contents of fruits, and yogurt for children have high sub-brand equity. Moreover, similarly positioned sub-brands could have distinct price premium, which could be attributed to the brand equity of the parent brand. Yogurt manufacturers operating in China may use this information to conduct cost-benefit analysis of introducing new attributes or developing new sub-brands. Also, distributing marketing resources effectively among different sub-brands is important in building successful sub-brands. Lastly, it needs to be noted that our findings are mainly empirical findings based on observational data; further 
studies may employ consumer survey to have a more precise understanding of the causes of the differences in price premiums of yogurt attributes and brand/sub-brand equities.

\section{Supplementary material}

Supplementary material can be found online at https://doi.org/10.22434/IFAMR2020.0040

Table S1. Sub-brand equity by city.

\section{Acknowledgements}

This work was supported by the Project of National Natural Science Foundation of China (No.71873051), (No. 72003074); the Philosophy and Social Sciences Project of Ministry of Education (No. 18YJA790033), (No. 19YJC630191); Capital Circulation Research Base, China (No. JD-YB- 2020-015), Fundamental Research Funds for the Central University (2662020JGPYG15), and the Opening project of Capital Circulation Industry Research Central (JD-KFKT-2020-002).

\section{References}

Aaker, D.A. 1992. The value of brand equity. Journal of Business Strategy 13(4): 27-32. https://doi.org/10.1108/ eb039503

Aaker, D.A. 1996. Measuring brand equity across products and markets. California Management Review 38(3): 102-120.

Baltas, G. and C. Saridakis. 2010. measuring brand equity in the car market: a hedonic price analysis. The Journal of the Operational Research Society 61(2): 284-293.

Bimbo, F., A. Bonanno and R. Viscecchia. 2016. Do health claims add value? The role of functionality, effectiveness and brand. European Review of Agricultural Economics 43(5): 761-780. https://doi. org/10.1093/erae/jbw002

Bonanno, A. 2016. A hedonic valuation of health and nonhealth attributes in the U.S. yogurt market. Agribusiness 32(3): 299-313. https://doi.org/10.1002/agr.21448

Bronnmann, J. and F. Asche. 2015. The value of product attributes, brands and private labels: an analysis of frozen seafood in Germany. Journal of Agricultural Economics 67(1): 231-244. https://doi. org/10.1111/1477-9552.12138

Carlucci, D., A. Stasi, G. Nardone and A. Seccia. 2013. Explaining price variability in the Italian yogurt market: a hedonic analysis. Agribusiness 29(2): 194-206.

China Ministry of Agriculture. 2017. China agricultural outlook (2017-2026). Report of the Market Early Warning Expert Committee. China Ministry of Agriculture, Beijing, China.

ChinaAg. 2018. Yogurt market brief. Available at: https://www.chinaag.org/2018/10/31/china-yogurt/

ChrHansen. 2019. Ambient yogurt - a category with untapped potential. Chr. Hansen Holding A/S, Hoersholm, Denmark. Available at: https://www.chr-hansen.com/en/food-cultures-and-enzymes/fresh-dairy/ cards/article-cards/ambient-yogurt

Costanigro, M., J.J. McCluskey, J.L. Lusk, J. Roosen and J.F. Shogren. 2011. Hedonic price analysis in food markets. In: J.L. Lusk, J. Roosen and J.F. Shogren (eds.) The Oxford handbook of the economics of food consumption and policy. Oxford University Press, Oxford, UK, pp. 153-161.

DaxueConsulting. 2019. Dairy products in China: how the country will overtake the US as the world's largest dairy market by 2022. Daxue Consulting, Beijing, China.

Fuller, F., J. Huang, H. Ma and S. Rozelle. 2006. Got milk? The rapid rise of China's dairy sector and its future prospects. Food Policy 31(3): 201-215. https://doi.org/10.1016/j.foodpol.2006.03.002

Hemme, T. and J. Otte. 2010. Status and prospects for smallholder milk production: a global perspective. Food and Agriculture Organization of the United Nations, Rome, Italy.

HexunNews. 2016. Advertising expenditure exceeding 15 bn yuan for four major dairy companies in China. Available at: http://stock.hexun.com/2016-05-05/183698226.html (in Chinese) 
Jin, Y.H., D. Zilberman, and A. Heiman. 2008. Choosing brands: fresh produce versus other products. American Journal of Agricultural Economics 90(2): 463-475. https://doi.org/10.1111/j.1467-8276.2007.01062.x

Keller, K.L. 1993. Conceptualizing, measuring, and managing customer-based brand equity. Journal of Marketing 57(1): 1-22.

Lancaster, K.J. 1966. A new approach to consumer theory. Journal of Political Economy 74(2): 132-157.

Rosen, S. 1974. Hedonic prices and implicit markets - product differentiation in pure competition. Journal of Political Economy 82(1): 34-55.

Schulz, L.L., T.C. Schroeder and K.L. White. 2012. Value of beef steak branding: hedonic analysis of retail scanner data. Agricultural and Resource Economics Review 41(2): 260.

Scourboutakos, M.J., B. Franco-Arellano, S.A. Murphy, S. Norsen, E.M. Comelli and M.R. L'Abbé. 2017. Mismatch between probiotic benefits in trials versus food products. Nutrients 9(4): 400.

Shum, M. 2004. Does advertising overcome brand loyalty? Evidence from the breakfast-cereals market. Journal of Economics \& Management Strategy 13(2): 241-272. https://doi.org/10.1111/j.15309134.2004.00010.x

Szathvary, S. and S. Trestini. 2014. A hedonic analysis of nutrition and health claims on fruit beverage products. Journal of Agricultural Economics 65(2): 505-517. https://doi.org/10.1111/1477-9552.12056

Vickner, S.S. 2015. Estimating the implicit price of convenience: a hedonic analysis of the US breakfast sausage market. Agribusiness 31(2): 281-292.

Wenqian, Z. 2017. Yogurt is top seller in dairy products. China Daily, October 24, 2017. Available at: http:// www.chinadaily.com.cn/business/2017-10/24/content_33636194.htm

Wenqian, Z. 2019. Dairy preferences diverge with age. China Daily, June 24, 2019. Available at: http:// global.chinadaily.com.cn/a/201906/24/WS5d1042d4a3103dbf14329dd6.html

Yoo, B., N. Donthu and S. Lee. 2000. An examination of selected marketing mix elements and brand equity. Journal of the Academy of Marketing Science 28(2): 195-211. 